\title{
Identification of new loci for salt tolerance in soybean by high-resolution genome- wide association mapping
}

Tuyen D. Do ${ }^{1,4}$, Tri D. Vuong ${ }^{1}$, David Dunn², Michael Clubb², Babu Valliyodann', Gunvant Patil ${ }^{1,5}$, Pengyin Chen², Dong $\mathrm{Xu}^{3}$, Henry T. Nguyen ${ }^{*^{*}}$ and J. Grover Shannon ${ }^{2^{*}}$

\begin{abstract}
Background: Salinity is an abiotic stress that negatively affects soybean [Glycine max (L.) Merr.] seed yield. Although a major gene for salt tolerance was identified and consistently mapped to chromosome (Chr.) 3 by linkage mapping studies, it does not fully explain genetic variability for tolerance in soybean germplasm. In this study, a genome-wide association study (GWAS) was performed to map genomic regions for salt tolerance in a diverse panel of 305 soybean accessions using a single nucleotide polymorphism (SNP) dataset derived from the SoySNP50K iSelect BeadChip. A second GWAS was also conducted in a subset of 234 accessions using another $3.7 \mathrm{M}$ SNP dataset derived from a whole-genome resequencing (WGRS) study. In addition, three gene-based markers (GBM) of the known gene, Glyma03g32900, on Chr. 3 were also integrated into the two datasets. Salt tolerance among soybean lines was evaluated by leaf scorch score (LSS), chlorophyll content ratio (CCR), leaf sodium content (LSC), and leaf chloride content (LCC).
\end{abstract}

Results: For both association studies, a major locus for salt tolerance on Chr. 3 was confirmed by a number of significant SNPs, of which three gene-based SNP markers, Salt-20, Salt14056 and Salt11655, had the highest association with all four traits studied. Also, additional genomic regions on Chrs. 1, 8, and 18 were found to be associated with various traits measured in the second GWAS using the WGRS-derived SNP dataset.

Conclusions: A region identified on Chr. 8 was identified to be associated with all four traits and predicted as a new minor locus for salt tolerance in soybean. The candidate genes harbored in this minor locus may help reveal the molecular mechanism involved in salt tolerance and to improve tolerance in soybean cultivars. The significant SNPs will be useful for marker-assisted selection for salt tolerance in soybean breeding programs.

Keywords: Soybean [Glycine max (L.) Merr.)], Salt tolerance, Genome-wide association study (GWAS), Single nucleotide polymorphism (SNP), Gene-based marker, Candidate genes

\section{Background}

In the worldwide crop agriculture, salinity is considered a major abiotic stress. The global extent of salt-affected soils amounts to 1128 million ha, of which $60 \%$ are saline soils, $26 \%$ are sodic soils, and $14 \%$ are saline-sodic soils [1]. Among irrigated agricultural land, an estimated 60 million ha is affected by salinity worldwide [2], and 0.25-0.5 million ha annual salt build-up causes

\footnotetext{
* Correspondence: nguyenhr@missouri.edu; shannong@missouri.edu 'Division of Plant Sciences, University of Missouri, Columbia, MO 65211, USA ${ }^{2}$ Division of Plant Sciences, University of Missouri, Portageville, MO 63873, USA

Full list of author information is available at the end of the article
}

significant loss of agricultural production [3]. The United States has large areas of soils with 5.2 million ha [2] or approximately $23 \%$ of the total irrigated land that is salt affected. Exploiting plant salinity tolerance has been shown to be among the effective strategies to limit losses from naturally occurring salinity and from the threat of human activities coupled with global climate changes $[2,4,5]$.

Although soybean is classified as a moderately salt tolerant crop plant with a threshold of $5 \mathrm{dS} / \mathrm{m}$, salt sensitive soybean cultivars were severely affected under salt stress and did not produce seeds at a soil salinity level of

(c) The Author(s). 2019 Open Access This article is distributed under the terms of the Creative Commons Attribution 4.0 International License (http://creativecommons.org/licenses/by/4.0/), which permits unrestricted use, distribution, and reproduction in any medium, provided you give appropriate credit to the original author(s) and the source, provide a link to the Creative Commons license, and indicate if changes were made. The Creative Commons Public Domain Dedication waiver (http://creativecommons.org/publicdomain/zero/1.0/) applies to the data made available in this article, unless otherwise stated. 
$8 \mathrm{dS} / \mathrm{m}[6,7]$. Soybean yield losses could result from reduced germination, low seedling emergence, and poor plant growth and development [8-11]. In addition, soybean seed protein, oil and carbohydrate content are negatively affected by salinity $[12,13]$.

Bi-parental quantitative trait locus (QTL) mapping was successfully implemented to identify and confirm a major locus on chromosome (Chr.) 03 for salt tolerance in soybean [14-20]. The candidate gene (Glyma03g32900) underlying salt tolerance was identified on Chr. 3 and related to a sodium transporter [17, 19, 21]. Near-isogenic lines carrying the salt tolerant gene were selected using molecular markers and showed high yield under saline field conditions [21, 22]. Gene-based makers (GBM) were developed for marker-assisted selection (MAS) and also for identifying new tolerance genes [20, 23]. Minor loci for salt tolerance were also identified on chromosomes (Chrs.) 2, 7, 9, 11, 13, 14, 15 and 18 [20, 24, 25]. In addition, other soybean sources may carry new gene(s) for salt tolerance $[15,19,23]$. Nevertheless, the major limitations of bi-parental linkage mapping can detect alleles from parents only and a few recombination events occur in mapping populations [26].

Genome-wide association studies (GWAS) present some advantages over linkage mapping among individuals in natural populations to exploit broader genetic diversity [27-29]. The concern for GWAS is spurious associations (false positive or Type I error) that can be caused by population stratification and cryptic relatedness [30-33]. However, various statistical procedures have been developed to reduce and control this issue. For instance, a Mixed Linear Model (MLM) with incorporation of population structure and a kinship matrix effectively eliminated false positives in GWAS [34, 35]. Multiple-Locus Linear Mixed Model (MLMM) was then developed based on MLM by adding significant markers as covariates in a stepwise MLM to remove the confounding effect between testing markers and relatedness $[36,37]$. The MLMM, with the advantage in controlling false positives, has been successful for association mapping in Arabidopsis, common wheat, rice, pea, sorghum, and tomato [38-43].

Recently, many plant genomes have been re-sequenced using next-generation sequencing (NGS) technologies. The exploration of whole-genome re-sequencing (WGRS) data was considered as one of the requirements for GWAS [44]. Sequence-based GWAS was successfully applied for mapping agronomic traits and identifying the candidate genes inside of significant genomic regions in rice, peach, and foxtail millet [45-47]. In a GWAS study in rice, in addition to the confirmation of the reported genes, new genes were identified for agronomic traits using WGRS data. The results of confirming those new genes by overexpression were highly accurate [48].
Although SNP chip data was successfully used in GWAS to provide valuable genetic information, the higher density of SNP data generated from WGRS would be more precise in determining the candidate genes controlling traits of interest $[45,48]$.

An association mapping study for salt tolerance was first reported in soybean by analyzing seed germination rate under salt conditions [49]. The study identified three genomic regions significantly associated with the ratio of imbibition rate, the ratio of germination index, and the ratio of germination rate under salt conditions and mapped to Chrs. 8, 9, and 18 [49]. The major locus for salt tolerance on Chr. 3 mapped by bi-parental linkage mapping was confirmed using SoySNP50K iSelect BeadChip and WGRS data of 106 soybean lines [23]. In addition to the major locus on Chr. 3, eight additional genomic regions significantly associated with both leaf chloride concentrations and leaf chlorophyll concentrations were mapped on Chrs. 2, 7, 8, 10, 13, 14, 16, and 20 using SoySNP50K iSelect BeadChip dataset and were recommended for future studies [50].

In this study, two SNP marker datasets, the SoySNP50K iSelect BeadChip accessed from the Soybase (http://www.soybase.org) and the WGRS-derived $3.7 \mathrm{M}$ SNPs, which were developed in the Soybean Genetics and Genomics Lab (Valliyodan and Nguyen, unpublished data), along with three salt tolerant GBMs [20,23] were used for association mapping of salt tolerance among soybean plant introductions (PIs) from a core collection (Drs. Cregan and Song, pers. comm.). The objectives of this study were to map additional loci for salt tolerance other than the known locus on Chr. 3 and to identify new sources of salt tolerance for genetic analysis and breeding to improve salt tolerance in soybean.

\section{Results}

\section{Phenotypic variation, heritability and correlation of salt tolerance traits}

Two salt-sensitive, Hutcheson and Jackson, and two salt-tolerant, Lee and Fiskeby III, checks were clustered into corresponding groups as shown in phenotypic tree (Additional file 1: Table S1; Additional file 2: Figure S1; Fig. 1). The phenotypic variation among 305 soybean lines was statistically significant for all traits studied, including leaf scorch score (LSS), chlorophyll content ratio (CCR), leaf sodium content (LSC) and leaf chloride content (LCC), ranging from 1 to $5,0.3-1.2,0.03-1.7\left(\mathrm{~g} \mathrm{~kg}^{-}\right.$ $\left.{ }^{1}\right)$ and 2.7-18.2 $\left(\mathrm{g} \mathrm{kg}^{-1}\right)$, respectively (Table 1$)$. Some soybean lines evaluated showed higher salt tolerance than the salt-tolerant checks and some soybean lines were more sensitive to salt than the sensitive checks.

Correlation coefficients and heritability were estimated for the four traits in the diverse panel. The Pearson correlations indicated a significant linear relationship 


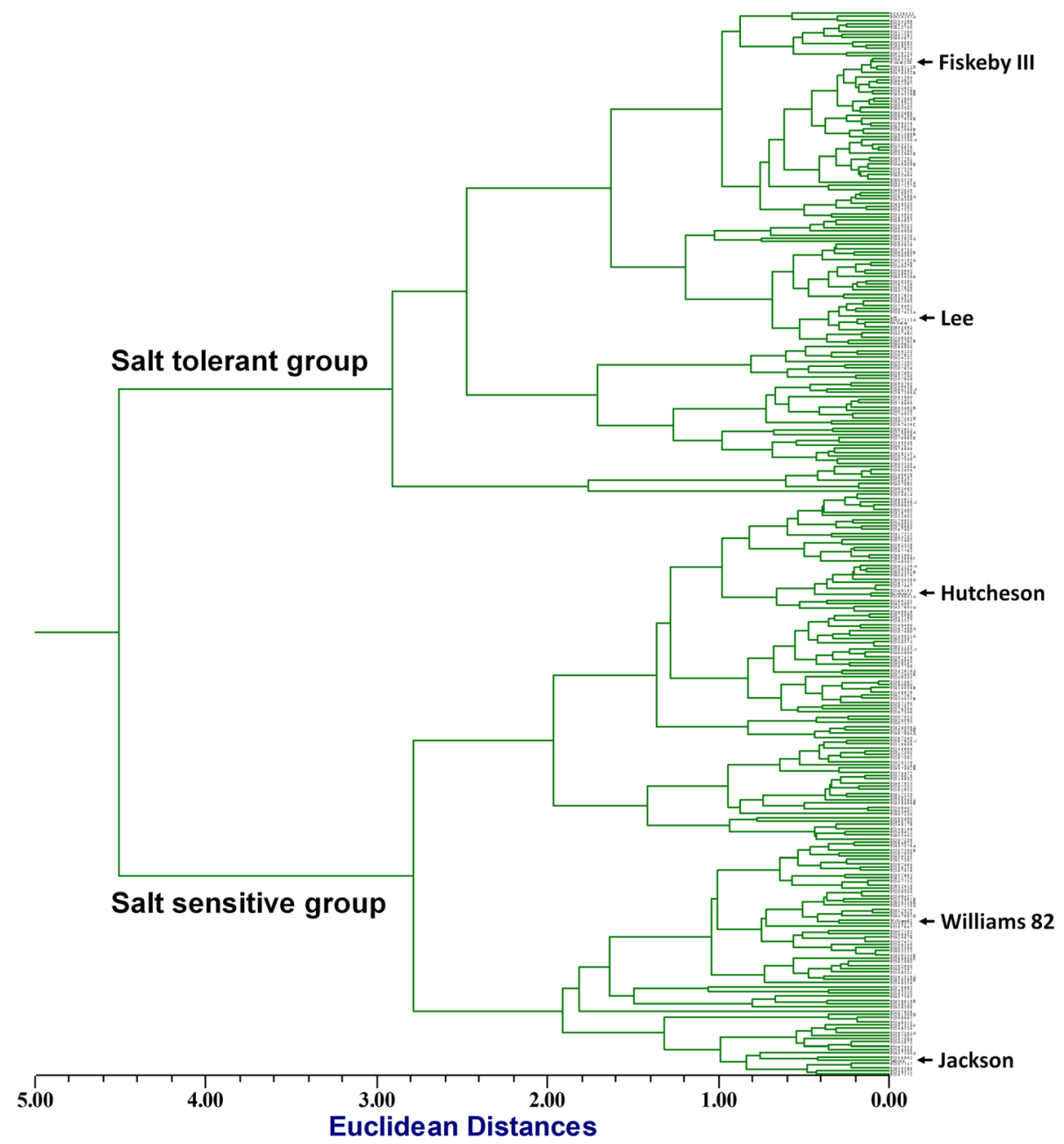

Fig. 1 Phenotypic dendrogram for salt tolerance variation among 305 soybean accessions. This was constructed by combining leaf scorch score (LSS), chlorophyll content ratio (CCR), leaf sodium content (LSC) and leaf chloride content (LCC)

among the four traits at $\alpha=0.01$. Among these, correlation coefficients $\left(r^{2}\right)$ of CCR with the other traits were negative and ranged from -0.92 to -0.61 . Conversely, the correlations between LSS, LSC and LCC were positive (Table 1). The broad-sense heritability was estimated based on analysis of variance for all traits (Table 1). The lowest value of heritability was 0.29 for LSC while higher heritability was observed in LSS, CCR and LCC as 0.82 ,
0.94 and 0.63 , respectively. These results indicate that all four measurements are valid and representative of salt tolerance and can be used in screening and selection for salt tolerance. However, LSC and CCR appear to be more feasible and efficient in a practical breeding program.

In addition, the variation among 305 soybean accessions was shown by combining the four traits to

Table 1 Statistics for salt tolerance traits of a diverse panel of 305 soybean accessions

\begin{tabular}{|c|c|c|c|c|c|c|c|c|c|}
\hline \multirow[t]{2}{*}{ Trait } & \multirow[t]{2}{*}{$\operatorname{Min}^{a}$} & \multirow[t]{2}{*}{$\operatorname{Max}^{\mathrm{b}}$} & \multirow[t]{2}{*}{ Mean } & \multirow{2}{*}{$\begin{array}{l}\text { Root } \\
\text { MSE }^{C}\end{array}$} & \multirow{2}{*}{$\begin{array}{l}C^{d} \\
(\%)\end{array}$} & \multirow[t]{2}{*}{$\mathrm{H}^{2 \mathrm{e}}$} & \multicolumn{3}{|c|}{ Pearson correlation } \\
\hline & & & & & & & $C C R$ & LSC & LCC \\
\hline LSS & 1.0 & 5.0 & 2.7 & 0.52 & 18.9 & 0.8 & $-0.922^{* *}$ & $0.638^{* *}$ & $0.743^{* *}$ \\
\hline CCR & 0.3 & 1.2 & 0.8 & 0.04 & 5.9 & 0.9 & & $-0.606^{* *}$ & $-0.700^{* *}$ \\
\hline LSC $\left(\mathrm{g} \mathrm{kg}^{-1}\right)$ & 0.03 & 1.70 & 0.45 & 0.31 & 76.98 & 0.29 & & & $0.692^{* *}$ \\
\hline LCC $\left(\mathrm{g} \mathrm{kg}^{-1}\right)$ & 2.70 & 18.20 & 7.85 & 1.74 & 22.21 & 0.63 & & & \\
\hline
\end{tabular}

LSS leaf scorch score, CCR chlorophyll content ratio, LSC leaf sodium content, LCC leaf chloride content

**: Correlation coefficients are significant at the 0.01 level (2-tailed)

${ }^{\mathrm{a}}$ : minimum; ${ }^{\mathrm{b}}$ : maximum; ${ }^{c}$ : square root of mean square error; ${ }^{\mathrm{d}}$ : coefficient of variation; ${ }^{\mathrm{e}}$ : Broad-sense heritability 
construct a phenotypic dendrogram into salt-tolerant and salt-sensitive groups. A dissimilarity matrix that measures the relative distance of each pairs in salt tolerance of soybean lines showed a range of Euclidean distance from 0.06 to 10.81 . The clustering analysis for the Euclidean distance matrix in the dendrogram revealed two main groups of soybean lines at the lowest Euclidean value and subgroups at higher values. Thereby, 137 soybean lines, including salt-tolerant checks belonged to salt-tolerant group and the remaining lines, including salt-sensitive checks were grouped into salt-sensitive group (Fig. 1).

\section{Linkage disequilibrium decay, population structure and relatedness among soybean accessions}

Linkage disequilibrium (LD) decay, population structure and relatedness were analyzed for the panel of 305 soybean accessions using 37,573 SNPs of the SoySNP50K dataset and for the subset of 234 accessions using over
3.7 M SNPs of the WGRS-derived SNP dataset. An average distance between two markers was approximately $29.36 \mathrm{~kb}$ for the SoySNP50K dataset and $0.43 \mathrm{~kb}$ for the WGRS-derived SNP dataset. LD decay on all adjacent SNP pairs are in nonlinear curves (Additional file 3: Figure S2) with the LD blocks at an $r^{2}$ of 0.2 with 293.64 and $371.42 \mathrm{~kb}$ for the SoySNP50K and the WGRS-derived SNP datasets, respectively. Thus, the number of SNPs was sufficient to cover the genome-wide haplotype blocks for both datasets.

The principal component analysis (PCA) showed that the variance explained, by eigenvalue of each $\mathrm{PC}$, rapidly dropped after the first 4 PCs for both SNP datasets (Fig. 2a). The cumulative eigenvalues of the first three PCs were 49.7 and $28.7 \%$ of variances for the diverse panel and the subset using the SoySNP50K and the WGRS-derived SNP datasets, respectively. For the diverse panel using 37,573 SNPs, 305 soybean accessions were separated into groups roughly corresponding to

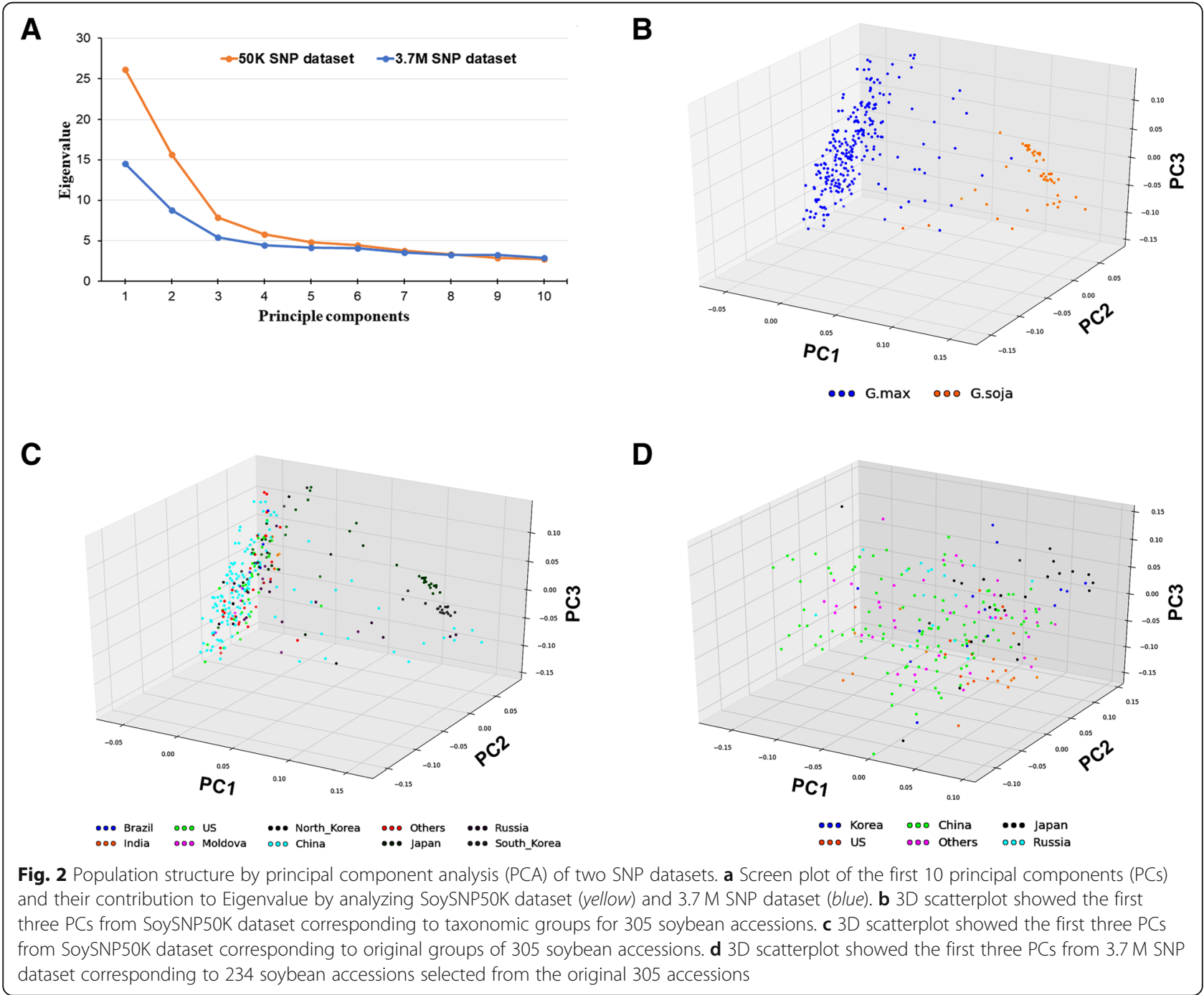


taxonomy (G. max and G. soja) and country of origin (Figs. 2b and c) according to the first three PCs. However, the subset of $234 \mathrm{G}$. $\max$ soybean accessions was less defined into groups based on the first three PCs using over 2.2 M SNPs (Fig. 2d).

The cryptic relatedness among soybean accessions was evaluated by kinship matrix from identity by state (IBS) each from paired soybean lines. The matrix with a range of IBS from 0.42 to 0.97 was calculated using the SoySNP50K dataset for the diverse panel to construct a phylogenetic tree showing the relationship among 305 soybean accessions (Fig. 3a). In this dendrogram, two main groups, G. $\max$ and G. soja, were clustered at the lowest IBS value and there were subgroups at higher IBS values. In a similar analysis, the kinship matrix with a narrower range of IBS from 0.52 to 0.89 was found by analyzing the WGRS-derived SNP dataset in the subset. The relatedness among 234 G. max soybean accessions was also shown in a heat map constructed from these IBS matrices (Fig. 3b).

The genomic inflation factors (lambda, $\lambda$ ) from association tests were applied to verify correction for population stratification by including PCs and kinship in the GWAS models (Additional file 4: Table S2). The lambda values from association tests for all traits were high using the general linear model (GLM) without correction for stratification with ranges of 2.21-3.95 and 1.442.08 by analyzing the SoySNP50K iSelect BeadChips and the WGRS-derived SNP datasets, respectively. The lower and closer to one values with a range of 1.05-1.20 were calculated with a population correction by $\mathrm{PCs}$ in $\mathrm{P}$ models. By adding more kinship matrices in EMMAX (Efficient mixed-model association expedited) and MLMM (Multi-locus mixed model) models, the pseudo-lambda values were from 0.93 to 1.03 for association of all traits from both genetic data sets indicating the GWAS results were not inflated by population structure or cryptic relatedness.

\section{GWAS for salt tolerance of the diverse panel using the SoySNP50K dataset}

After marker quality control and assurance, a total of 37,573 polymorphic SNPs were selected from the SoySNP50K dataset and were utilized for further analysis of LSS, CCR, LSC, and LCC in the diverse panel. The quantile-quantile (Q-Q) distributions showed most SNPs matched what was expected (Additional file 5: Figure S3). The inflation values (Additional file 4: Table S2), the EMMAX and MLMM with corrections for the population stratification from the kinship matrix and the three first PCs were optimal for all four traits evaluated in this study. Numbers of SNPs significantly associated with LSS, CCR, LSC, and LCC were 44, 38, 13, and 54 based on corrections Benjamini-Hochberg of False Discovery Rate $(F D R) \leq 0.05$. SNPs surrounding the known salt tolerance gene on Chr. 3 were the most significant in all four traits (Table 2; Fig. 4b). In addition, several SNPs significantly associated with one or two traits were identified on other chromosomes using the EMMAX analysis such as ss715616720 on Chr. 13 significantly associated with LSS and CCR, ss715609949 on Chr. 11 and ss715611871 on Chr. 12 with LSC, ss715592375 on Chr.

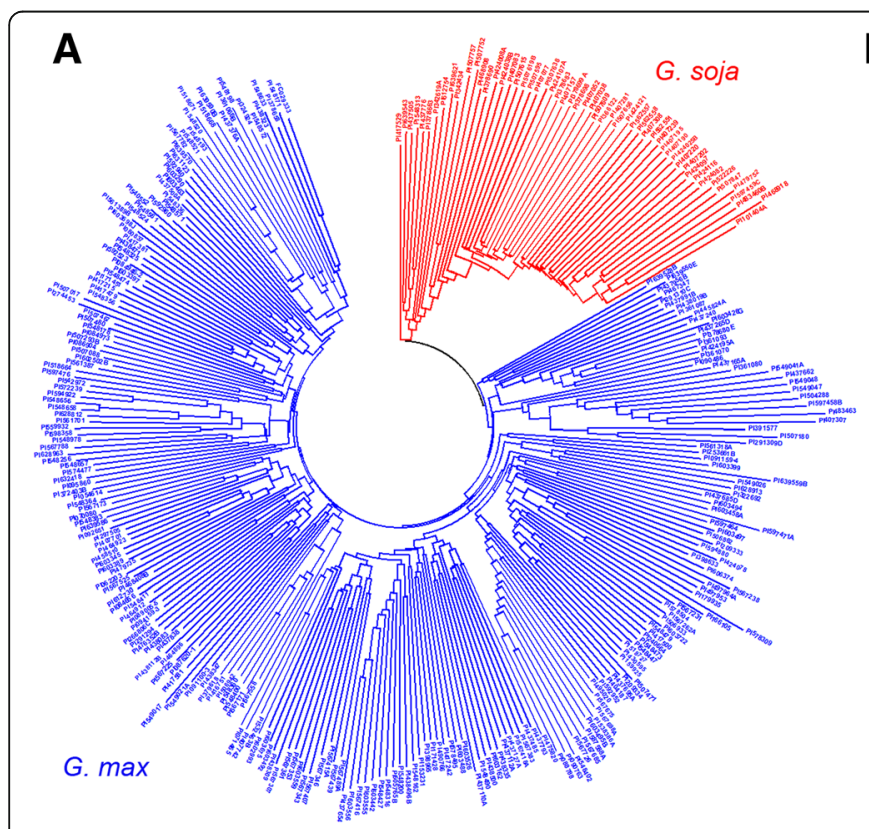

B

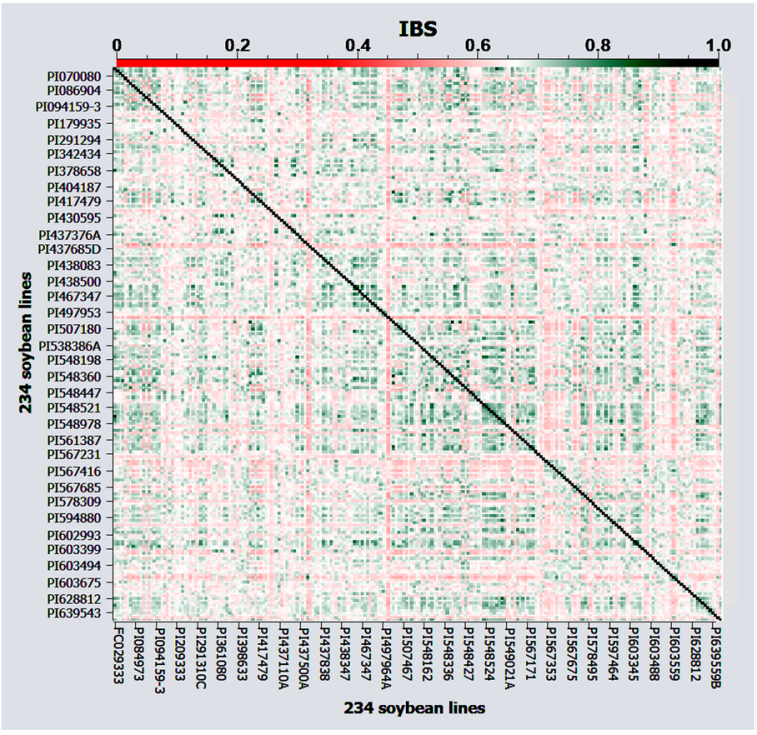

Fig. 3 Relationships among soybean accessions using SoySNP50K and 3.7 M SNP datasets. a Phylogenetic tree of 305 soybean accessions using SoySNP50K dataset. b Heatmap plot showing the relationship among 234 soybean accessions using 3.7 M SNP dataset 
Table 2 Several SNPs significantly associated with salt tolerance evaluated in GWAS using the SoySNP50K dataset for 305 soybean accessions

\begin{tabular}{|c|c|c|c|c|c|c|c|c|c|c|c|}
\hline \multirow[t]{2}{*}{ Marker } & \multirow[t]{2}{*}{ Chr. } & \multirow[t]{2}{*}{ Position } & \multicolumn{4}{|c|}{$-\log 10(P)$} & \multirow{2}{*}{$\begin{array}{l}\text { Call } \\
\text { Rate } \\
(\%)\end{array}$} & \multirow[t]{2}{*}{ MA } & \multirow[t]{2}{*}{ MAF } & \multirow{2}{*}{$\begin{array}{l}\text { Allele } \\
\text { Refer }\end{array}$} & \multirow{2}{*}{$\begin{array}{l}\text { Cloned/ } \\
\text { Candidate genes } \\
\text { a }\end{array}$} \\
\hline & & & LSS & CCR & LSC & LCC & & & & & \\
\hline Salt-20 & 3 & $38,610,964$ & $23.9^{*}$ & $22.3^{*}$ & $7.2^{*}$ & $25.7^{*}$ & 99.7 & c & 0.40 & $\mathrm{C} / \mathrm{G}$ & Glyma03g32900 b \\
\hline Salt14056 & 3 & $38,619,995$ & $28.9^{*}$ & $24.7^{*}$ & $10.3^{*}$ & $29.1^{*}$ & 100 & G & 0.44 & $\mathrm{C} / \mathrm{G}$ & Glyma03g32900 b \\
\hline Salt1 1655 & 3 & $38,622,492$ & $24.4^{*}$ & $22.5^{*}$ & $7.8^{*}$ & $27.9^{*}$ & 99.7 & T & 0.41 & $\mathrm{G} / \mathrm{T}$ & Glyma03g32900 b \\
\hline ss715592375 & 5 & $7,534,622$ & $2.5 \mathrm{~ns}$ & $3.1 \mathrm{~ns}$ & $2.4 \mathrm{~ns}$ & $4.7^{*}$ & 98.0 & G & 0.22 & $A / G$ & No gene \\
\hline ss715609949 & 11 & $27,743,052$ & $3.8 \mathrm{~ns}$ & $2.6 \mathrm{~ns}$ & $5.6^{*}$ & $4.1 \mathrm{~ns}$ & 99.0 & A & 0.06 & $\mathrm{G} / \mathrm{A}$ & No gene \\
\hline ss715611871 & 12 & $20,568,054$ & $2.6 \mathrm{~ns}$ & $2.5 \mathrm{~ns}$ & $4.8^{*}$ & $3.3 \mathrm{~ns}$ & 99.3 & T & 0.10 & $\mathrm{G} / \mathrm{T}$ & No gene \\
\hline ss715616720 & 13 & $16,871,244$ & $5.8^{*}$ & $4.9^{*}$ & $1.8 \mathrm{~ns}$ & $3.2 \mathrm{~ns}$ & 99.7 & T & 0.31 & $C / T$ & No gene \\
\hline ss715623199 & 15 & $9,138,970$ & $4.4^{*}$ & $2.2 \mathrm{~ns}$ & $1.0 \mathrm{~ns}$ & $1.3 \mathrm{~ns}$ & 100 & T & 0.24 & $C / T$ & Glyma.15 g116200 \\
\hline \multicolumn{3}{|c|}{$-\log 10(P)$ threshold $^{c}$} & 4.4 & 4.3 & 4.8 & 4.2 & & & & & \\
\hline
\end{tabular}

LSS leaf scorch score, CCR chlorophyll content ratio, LSC leaf sodium content, LCC leaf chloride content (LCC)

*: Significant association with salt tolerant traits; ns: None significant association with trait

${ }^{a}$ : The candidate gene in Soybase Wm82 Genome Browser version 2 consist of significant SNP; ${ }^{b}$ : The cloned gene for salt tolerance is named Glyma03g32900 in SoyBase Wm82 Genome Browser version 1; ${ }^{c}$ : Threshold was calculated based on P-value using False Discovery Rate correction (Benjamini-Hochberg); MA: Minor allele; MAF: Minor allele frequency

5 with LCC, and ss715592375 on Chr. 15 with LSS (Table 2; Fig. 4a). However, those significant SNPs, except the GBMs, were not detected after step 1 of MLMM.

\section{GWAS for salt tolerance of the subset using the WGRS- derived SNP dataset}

The subset of $234 \mathrm{G}$. max soybean accessions with $3.7 \mathrm{M}$ SNPs derived from the WGRS project (http://www.soybase. org) was chosen to further perform GWAS for salt tolerance. To ensure that population size had no effect on GWAS results, this subset was analyzed separately by reusing SoySNP50K dataset. Similar results were found compared to GWAS of salt tolerance using SoySNP50K dataset for the diverse panel of 305 soybean lines. However, only the major locus on Chr. 3 was detected (Additional file 6: Figure S4).

The SNPs derived from the WGRS project were subjected to further quality control and assurance with MAF $>0.05$ and the call rate $>0.95$. Over $2.2 \mathrm{M}$ polymorphic SNPs were obtained for further analysis. This dataset was employed for LD calculation, kinship construction, PCA, genotype association tests, and subsequently for GWAS of the four salt tolerant traits. Based on the Q-Q distributions most SNPs matched according to expectations (Additional file 7: Figure S5). In GWAS mixed models, the inflation values (Additional file 4: Table S2), with six PCs as a fixed effect and the kinship matrix as a random effect, were optimal for controlling confounding risk due to population stratification. The numbers of SNPs significantly associated with LSS, CCR, LSC and LCC from the EMMAX model analysis were 217, 190, 136 and 278, respectively, based on a FDR correction (Benjamini-Hochberg) with $\mathrm{FDR} \leq 0.05$ and selecting causal SNPs surrounding the know gene on Chr. 3. The significant SNPs associated with salt tolerant traits were located on Chrs. 1, 2, 3, 5, 6, 8, 14, 15, 16, 18, 19 and 20 (Fig. 5a) and the most significant SNPs on each chromosome are listed in Table 3. SNPs inside the known gene for salt tolerance with the highest $-\log 10(P)$ values, including three GBMs on Chr. 3, were significantly associated with all of four traits. Genomic regions on Chrs. 8 and 18 were also significantly associated with LSS, CCR, LSC and LCC, of which two adjacent peaks were in the significant region on Chr. 8. In addition, GWAS for salt tolerance using MLMM indicated that the significant positions in Chrs. 1, 3, 8 and 18 genomic regions were added as covariates (the most significant SNP after each step in the stepwise analysis) in the stepwise analysis (Fig. 6). Results show, the positions on Chr. 3 and Chr. 8 appeared to be associated with all of 4 salt tolerant traits while the positions on Chr. 1 and Chr. 18 were covariates in GWAS for LSC and LCC. Thus, the genomic region on Chr. 8 (Fig. 5B) is suggested as a minor locus for salt tolerance in addition to the major gene on Chr. 3 and the other significant genomic regions associated with individual traits measured to detect salt tolerance in this study.

\section{Putative candidate genes underlying salt tolerance}

Phytozome and Soybase genome browsers (https://phytozome.jgi.doe.gov/jbrowse/ and https://soybase.org/gb2/ gbrowse/) were used to detect additional genes in the significant genomic regions associated with salt tolerant traits in addition to the known gene on Chr. 3. The genomic intervals with the group of the significant SNPs ranged from 2788 to $787,140 \mathrm{bp}$ and were considered significant genomic regions to search for putative candidate genes. A total of 222 genes were found in the significant genomic intervals (Additional file 8: Table S3) including the genes underlying the most significant SNPs 


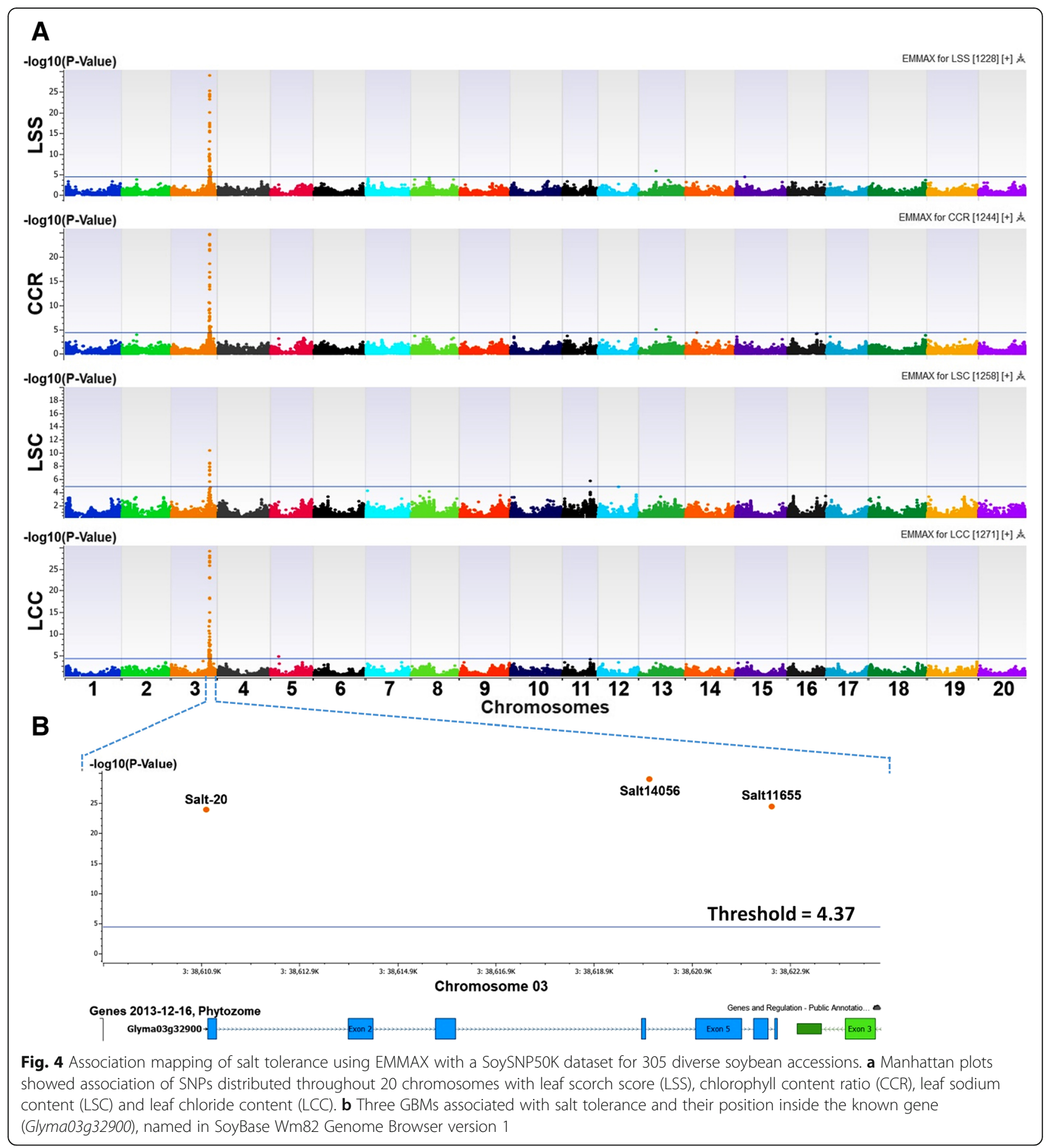

on each chromosome (Table 3). Among these, 157 genes have predicted functions and known protein families in Phytozome and Soybase databases. Based on functional annotation, transporters (Glyma.08 g146100, Glyma.08 g224400), ion channel (Glyma.02g204300), membrane proton pump (Glyma.08 g225500), universal stress protein (Glyma.14g211300), and Callose synthase (Glyma.08 g157400) could be additional candidate genes related to salt tolerance in soybean. Four genes were located in two adjacent, significant genomic intervals surrounding the minor locus on Chr. 8 and others on Chrs. 2 and 14.

\section{Identification of new sources of salt tolerance}

Soybean accessions belonging to salt tolerant and salt sensitive groups were classified by combining results of LSS, CCR, LSC and LCC (Fig. 2) and were tested with 


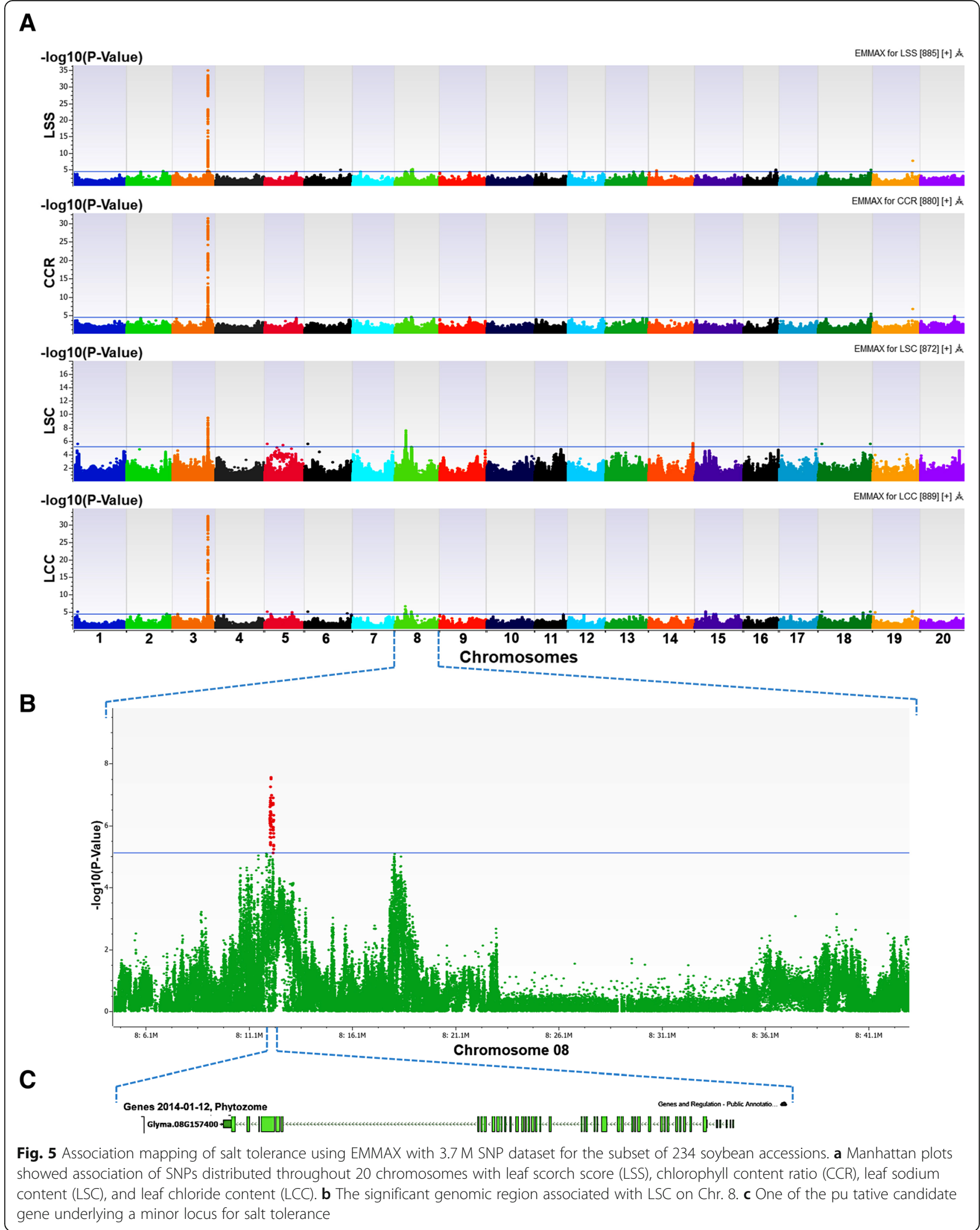


Table 3 The most significant SNPs on each chromosome associated with salt tolerance traits detected in an association analysis using the WGRS-derived SNP dataset in the subset of 234 soybean accessions

\begin{tabular}{|c|c|c|c|c|c|c|c|c|c|c|c|}
\hline \multirow[t]{2}{*}{ Marker } & \multirow[t]{2}{*}{ Chr. } & \multirow[t]{2}{*}{ Position } & \multicolumn{4}{|c|}{$-\log 10(P)$} & \multirow{2}{*}{$\begin{array}{l}\text { Call } \\
\text { Rate } \\
(\%)\end{array}$} & \multirow[t]{2}{*}{ MA } & \multirow[t]{2}{*}{ MAF } & \multirow{2}{*}{$\begin{array}{l}\text { Allele } \\
\text { Refer }\end{array}$} & \multirow{2}{*}{$\begin{array}{l}\text { Cloned/ } \\
\text { Candidate genes } \\
\text { a }\end{array}$} \\
\hline & & & LSS & CCR & LSC & LCC & & & & & \\
\hline 1:4591993-SNV & 1 & 4,591,993 & $1.1 \mathrm{~ns}$ & $2.3 \mathrm{~ns}$ & $5.5^{*}$ & $4.9^{*}$ & 100 & $\mathrm{~T}$ & 0.50 & $\mathrm{~T} / \mathrm{C}$ & No gene \\
\hline 2:38974662-SNV & 2 & $38,974,662$ & $4.5^{*}$ & $3.0 \mathrm{~ns}$ & $0.7 \mathrm{~ns}$ & $3.4 \mathrm{~ns}$ & 100 & T & 0.41 & T/A & No gene \\
\hline 2:43513959-SNV & 2 & $43,513,959$ & $4.0 \mathrm{~ns}$ & $2.3 \mathrm{~ns}$ & $1.1 \mathrm{~ns}$ & $4.4^{*}$ & 100 & $C$ & 0.49 & $\mathrm{~T} / \mathrm{C}$ & Glyma.02 g247400 \\
\hline Salt-20 & 3 & $38,610,964$ & $29.0^{*}$ & $25.6^{*}$ & $7.2^{*}$ & $27.4^{*}$ & 99.6 & C & 0.45 & $C / G$ & Glyma03g32900 b \\
\hline Salt14056 & 3 & $38,619,995$ & $32.4^{*}$ & $28.2^{*}$ & $8.2^{*}$ & $29.6^{*}$ & 100 & G & 0.46 & $C / G$ & Glyma03g32900 b \\
\hline Salt11655 & 3 & $38,622,492$ & $27.2^{*}$ & $24.1^{*}$ & $6.2^{*}$ & $25.7^{*}$ & 99.6 & $\mathrm{~T}$ & 0.45 & $\mathrm{G} / \mathrm{T}$ & Glyma03g32900 b \\
\hline 5:2725777-SNV & 5 & $2,725,777$ & $1.1 \mathrm{~ns}$ & $2.3 \mathrm{~ns}$ & $5.5^{*}$ & $4.9^{*}$ & 100 & $\mathrm{~T}$ & 0.50 & $\mathrm{~T} / \mathrm{C}$ & Glyma.05 g031300 \\
\hline 6:3536892-SNV & 6 & $3,536,892$ & $1.1 \mathrm{~ns}$ & $2.3 \mathrm{~ns}$ & $5.5^{*}$ & $4.9^{*}$ & 100 & A & 0.50 & $\mathrm{~A} / \mathrm{G}$ & No gene \\
\hline 6:38850839-SNV & 6 & $38,850,839$ & $4.8^{*}$ & $2.9 \mathrm{~ns}$ & $2.2 \mathrm{~ns}$ & $5.2^{*}$ & 100 & A & 0.25 & $\mathrm{~A} / \mathrm{G}$ & No gene \\
\hline 8:11762527-SNV & 8 & $11,762,527$ & $4.2 \mathrm{~ns}$ & $3.7 \mathrm{~ns}$ & $5.2^{*}$ & $6.6^{*}$ & 100 & $\mathrm{~T}$ & 0.35 & T/A & No gene \\
\hline 8:11859355-SNV & 8 & $11,859,355$ & $4.3^{*}$ & $3.4 \mathrm{~ns}$ & $3.6 \mathrm{~ns}$ & $5.3^{*}$ & 100 & $\mathrm{~T}$ & 0.32 & T/A & No gene \\
\hline 8:11869912-SNV & 8 & $11,869,912$ & $4.1 \mathrm{~ns}$ & $3.3 \mathrm{~ns}$ & $3.5 \mathrm{~ns}$ & $5.0^{*}$ & 100 & $\mathrm{~T}$ & 0.3 & T/C & Glyma.08 g153800 \\
\hline 8:11897542-SNV & 8 & $11,897,542$ & $4.1 \mathrm{~ns}$ & $3.3 \mathrm{~ns}$ & $3.3 \mathrm{~ns}$ & $4.6^{*}$ & 100 & $C$ & 0.3 & $C / T$ & Glyma.08 g154400 \\
\hline 8:12168563-SNV & 8 & $12,168,563$ & $3.3 \mathrm{~ns}$ & $3.5 \mathrm{~ns}$ & $6.7^{*}$ & $4.4^{*}$ & 100 & G & 0.38 & $\mathrm{G} / \mathrm{A}$ & Glyma.08 g157400 \\
\hline 8:12177874-SNV & 8 & $12,177,874$ & $2.9 \mathrm{~ns}$ & $3.7 \mathrm{~ns}$ & $6.9^{*}$ & $3.4 \mathrm{~ns}$ & 100 & A & 0.48 & $A / T$ & Glyma.08 g157400 \\
\hline 8:12198547-SNV & 8 & $12,198,547$ & $3.8 \mathrm{~ns}$ & $4.1 \mathrm{~ns}$ & $7.6^{*}$ & $4.6^{*}$ & 100 & $C$ & 0.4 & $C / T$ & No gene \\
\hline 8:12221598-SNV & 8 & $12,221,598$ & $3.0 \mathrm{~ns}$ & $2.8 \mathrm{~ns}$ & $6.7^{*}$ & $4.3 \mathrm{~ns}$ & 100 & G & 0.4 & $\mathrm{G} / \mathrm{A}$ & Glyma.08 g157700 \\
\hline 8:18197526-SNV & 8 & $18,197,526$ & $3.5 \mathrm{~ns}$ & $3.2 \mathrm{~ns}$ & $3.1 \mathrm{~ns}$ & $5.0^{*}$ & 100 & $\mathrm{~T}$ & 0.07 & $\mathrm{~T} / \mathrm{C}$ & Glyma.08 g224400 \\
\hline 8:18363900-SNV & 8 & $18,363,900$ & $4.5^{*}$ & $3.6 \mathrm{~ns}$ & $2.2 \mathrm{~ns}$ & $4.6^{*}$ & 100 & A & 0.47 & $A / G$ & No gene \\
\hline 8:18378659-SNV & 8 & $18,378,659$ & $4.8^{*}$ & $4.5^{*}$ & $3.3 \mathrm{~ns}$ & $3.7 \mathrm{~ns}$ & 100 & G & 0.48 & $T / G$ & No gene \\
\hline 14:8102511-SNV & 14 & $8,102,511$ & $4.6^{*}$ & $3.7 \mathrm{~ns}$ & $1.2 \mathrm{~ns}$ & $2.2 \mathrm{~ns}$ & 100 & $\mathrm{~T}$ & 0.49 & T/C & No gene \\
\hline 14:47627721-SNV & 14 & $47,627,721$ & $1.2 \mathrm{~ns}$ & $0.9 \mathrm{~ns}$ & $5.6^{*}$ & $0.9 \mathrm{~ns}$ & 100 & A & 0.06 & $\mathrm{~A} / \mathrm{G}$ & Glyma.14 g211300 \\
\hline 15:11833367-SNV & 15 & $11,833,367$ & $3.0 \mathrm{~ns}$ & $2.4 \mathrm{~ns}$ & $3.4 \mathrm{~ns}$ & $5.0^{*}$ & 100 & $C$ & 0.49 & $C / T$ & Glyma.15 g143900 \\
\hline 16:34944055-SNV & 16 & $34,944,055$ & $4.9^{*}$ & $4.1 \mathrm{~ns}$ & $1.3 \mathrm{~ns}$ & $2.4 \mathrm{~ns}$ & 100 & $C$ & 0.37 & $C / A$ & No gene \\
\hline 18:56065139-SNV & 18 & $56,065,139$ & $1.1 \mathrm{~ns}$ & $2.3 \mathrm{~ns}$ & $5.5^{*}$ & $4.9^{*}$ & 100 & G & 0.50 & $\mathrm{G} / \mathrm{T}$ & Glyma.18 g294400 \\
\hline 18:57153685-SNV & 18 & $57,153,685$ & $3.2 \mathrm{~ns}$ & $5.3^{*}$ & $0.8 \mathrm{~ns}$ & $3.2 \mathrm{~ns}$ & 100 & $\mathrm{~T}$ & 0.23 & T/C & No gene \\
\hline 18:57203235-SNV & 18 & $57,203,235$ & $4.9^{*}$ & $4.1 \mathrm{~ns}$ & $2.5 \mathrm{~ns}$ & $2.9 \mathrm{~ns}$ & 100 & A & 0.17 & $A / T$ & No gene \\
\hline 19:43567289-SNV & 19 & $43,567,289$ & $7.5^{*}$ & $6.7^{*}$ & $2.1 \mathrm{~ns}$ & $5.1^{*}$ & 100 & $\mathrm{~T}$ & 0.20 & $T / G$ & Glyma.19g175600 \\
\hline 20:37261341-SNV & 20 & $37,261,341$ & $3.3 \mathrm{~ns}$ & $4.6^{*}$ & $0.5 \mathrm{~ns}$ & $1.6 \mathrm{~ns}$ & 100 & $C$ & 0.06 & $\mathrm{~T} / \mathrm{C}$ & No gene \\
\hline$-\log 10(P)$ threshold $^{c}$ & & & 4.3 & 4.4 & 5.1 & 4.3 & & & & & \\
\hline
\end{tabular}

LSS leaf scorch score, CCR chlorophyll content ratio, LSC leaf sodium content, LCC leaf chloride content (LCC)

*: Significant association with salt tolerant traits; ns: None significant association with trait

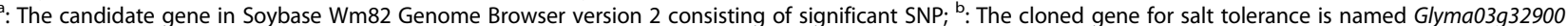
in SoyBase Wm82 Genome Browser version 1; ${ }^{\mathrm{C}}$ : Threshold was calculated based on P-value using False Discovery Rate correction (Benjamini-Hochberg); MA Minor allele; MAF: Minor allele frequency

genotypes of three GBMs. To evaluate the genotype-phenotype association, genotypes of GBMs (Salt-20, Salt14056 and Salt11655) among 305 soybean accessions were classified and evaluated by compatibility with phenotypes. The GBM genotypes of salt tolerant checks (Fiskeby III and Lee) were classified as mutant (mut) alleles while those of salt sensitive checks (Hutcheson and Jackson) were wide-type (wt) alleles (Table 4). There was a strong genotype-phenotype association in the diverse panel of soybean accessions. Over $90 \%$ of the accessions had a perfect genotype-phenotype match, in which salt tolerant and salt sensitive lines carried mutant and wide-type alleles of all three GBMs, respectively. There were some salt sensitive lines with recombination of the three GBMs; however, no salt sensitive lines carried mutant alleles of all three GBMs. In the salt tolerant group, 9 lines had a combination of three GBMs (Table 4), suggesting that these soybean accessions may be new salt tolerant sources with new alleles of the known salt tolerant gene on Chr. 3. Additionally, another six lines 


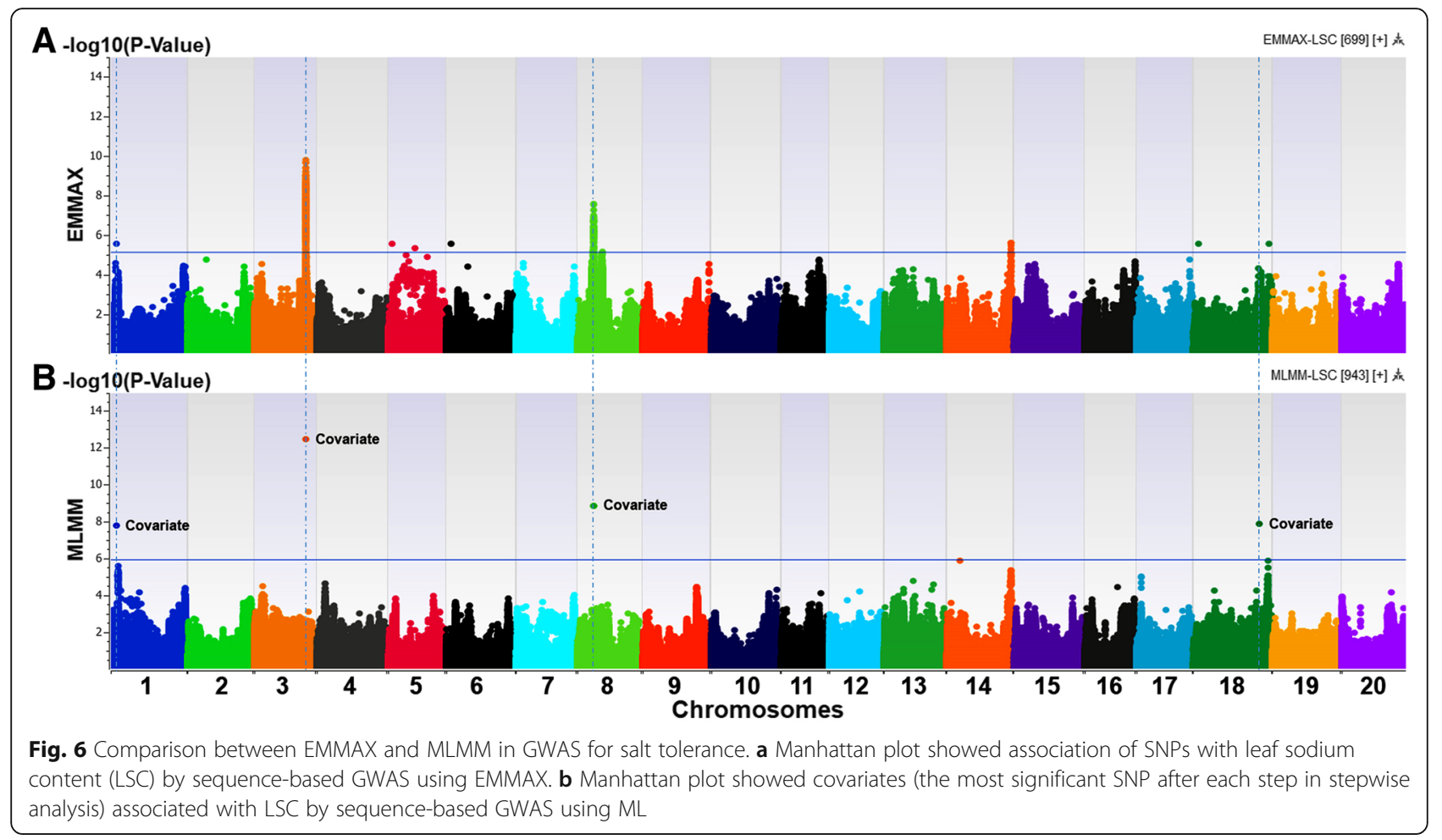

Table 4 New sources for salt tolerance from matching analysis of phenotype and gene-based marker genotypes

\begin{tabular}{|c|c|c|c|c|c|c|}
\hline \multirow[t]{2}{*}{$\mathrm{Pl}$} & \multirow[t]{2}{*}{ Taxonomy } & \multirow{2}{*}{$\begin{array}{l}\text { Phenotypic } \\
\text { Group }\end{array}$} & \multicolumn{3}{|c|}{ Genotypes of GBMs } & \multirow{2}{*}{$\begin{array}{l}\text { Prediction/ } \\
\text { Suggestion }\end{array}$} \\
\hline & & & Salt-20 & Salt14056 & Salt11655 & \\
\hline Pl597458B & G. soja & Tolerant & Wt & Mut & Mut & New allele on Chr. 3 \\
\hline PI342434 & G. $\max$ & Tolerant & Wt & Mut & Wt & New allele on Chr. 3 \\
\hline PI548198 & G. $\max$ & Tolerant & Wt & Mut & Wt & New allele on Chr. 3 \\
\hline PI561389B & G. $\max$ & Tolerant & Wt & Mut & Wt & New allele on Chr. 3 \\
\hline PI407202 & G. soja & Tolerant & Wt & Mut & Wt & New allele on Chr. 3 \\
\hline PI407220 & G. soja & Tolerant & Wt & Mut & Wt & New allele on Chr. 3 \\
\hline PI424107A & G. soja & Tolerant & Wt & Mut & Wt & New allele on Chr. 3 \\
\hline PI479752 & G. soja & Tolerant & Wt & Mut & Wt & New allele on Chr. 3 \\
\hline PI407083 & G. soja & Tolerant & Wt & Wt & Mut & New allele on Chr. 3 \\
\hline PI468908 & G. $\max$ & Tolerant & Wt & Wt & Wt & New gene \\
\hline PI080837 & G. $\max$ & Tolerant & Wt & Wt & Wt & New gene \\
\hline PI417500 & G. $\max$ & Tolerant & Wt & Wt & Wt & New gene \\
\hline PI424116 & G. soja & Tolerant & Wt & Wt & Wt & New gene \\
\hline PI483460B & G. soja & Tolerant & Wt & Wt & Wt & New gene \\
\hline PI562551 & G. soja & Tolerant & Wt & Wt & Wt & New gene \\
\hline PI438471 & G. $\max$ & Tolerant check & Mut & Mut & Mut & \\
\hline PI548656 & G. max & Tolerant check & Mut & Mut & Mut & \\
\hline PI518664 & G. max & Sensitive check & Wt & Wt & Wt & \\
\hline PI548657 & G. $\max$ & Sensitive check & Wt & Wt & Wt & \\
\hline
\end{tabular}

Wt: Wide-type allele of GBMs (Salt-20, Salt14056, Salt11655)

Mut: Mutant allele of GBMs (Salt-20, Salt14056, Salt11655) 
without mutant alleles of the three GBMs (Table 4) were predicted as salt tolerant sources carrying new gene(s) for salt tolerance in soybean. Additional studies are need to confirm such predictions.

\section{Discussion}

The association mapping approach is suited for the detection and characterization of quantitative traits because of broad genetic base of natural populations [2729]. The development of statistical models and multiple tests to control effects of population structure and relatedness [34-37], as well as exploration of whole-genome sequencing data, has made GWAS more efficient in identifying the significant genomic regions associated with the traits of interest and in predicting candidate genes $[45,48]$. In this study, both SoySNP50Kand WGRS-derived SNP datasets were sufficient to cover the genome-wide haplotype blocks. There was no genomic inflation by population stratification found in the association analysis using EMMAX and MLMM (Additional file 5: Figure S3 and Additional file 7: Figure S5; Additional file 4: Table S2). Nevertheless, GWAS for detecting salt tolerance using the SoySNP50K dataset only confirmed the major locus on Chr. 3. On the other hand, using the $3.7 \mathrm{M} \mathrm{SNP}$ dataset discovered more significant genomic regions, including a minor locus on Chr. 8. Additionally, three GBMs of the known gene (Glyma03g32900) on Chr. 3 [17, 19, 21] were significantly associated with salt tolerance by SoySNP50K-based GWASs (Fig. 4b) while there were many other significant SNPs in the known gene identified by WGRS-based GWASs (Additional file 9: Figure S6). Pinpointing the known gene was only accomplished by integration of GBMs into the SoySNP50K dataset. Therefore, a larger SNP dataset generated from whole-genome sequencing was better for GWAS to detect new loci for salt tolerance.

The major locus on Chr. 3, in which the known gene for salt tolerance (Glyma03g32900) was confirmed by previous GWAS $[23,50]$. By integrating the three GBMs into the SNP marker datasets, the known gene was pinpointed with the most significant SNPs associated with all four traits by both SoySNP50K- and WGRS-based GWAS (Tables 2 and 3; Figs. 4a and 5a). Also, the other genomic regions associated with four traits have been mapped by association mapping in previous studies. A GWAS analysis of 191 landraces for three germination-related traits under high salt conditions using 1142 SNPs determined 13 SNPs associated with salt tolerance on Chrs. 2, 3, 6, 8, $9,12,13,14,17$ and 18 and were reported with a $\log 10(P)$ range of 2.05-3.60 by using a mixed linear model [49]. In a previous association study of a panel of 283 soybean lines with 33,009 SNPs (SoySNP50K dataset), Zeng et al. [50] evaluated two traits, leaf chloride concentrations and leaf chlorophyll concentrations, and confirmed the major locus on Chr. 3 and detected additional genomic regions on Chrs. $2,7,8,10,13,14,16$ and 20 with $-\log 10(P)>4.1$ and $-\log 10(P)>2.1$ thresholds for a GLM and MLM, respectively. The results of those association mapping studies require a confirmation because of $-\log 10(P)$ thresholds to control spurious association did not meet the requirements for GWAS $[49,50]$. In our study, the significant SNPs associated with salt tolerance using both SNP marker datasets were found on 15 chromosomes based on the Benjamini-Hochberg correction with FDR $\leq 0.05$ (Tables 2 and 3). Consequentially, the major locus on Chr. 3 , minor locus on Chr. 8, and significant genomic regions on Chrs. 1 and 18 were confirmed and identified by a combination an association of salt tolerant traits and results of GWAS using MLMM. Comparing to previous studies, the minor locus on Chr. 8 identified in our study was $1,449,275 \mathrm{bp}$ away from BARC-041663-08059 associated with germination-related traits under salt stress [49] and $17,932,879$ bp away from ss715601563 associated with salt tolerance [50]. Thus, the significant genomic region on Chr. 8 associated with salt tolerance in this study strongly predicts a new minor locus for salt tolerance in soybean.

In addition, a $\mathrm{Cl}^{-}$-tolerant QTL located between 27,665,585 and 28,206,014 bp on Chr. 13 was identified by linkage mapping of $\mathrm{KCl}$-salt tolerance [25]. Another QTL for leaf sodium content was mapped between 38,366,685 and 40,167,119 bp on Chr. 13 [20]. In our study only one SNP marker, ss715616720, was significantly associated with leaf scorch score and chlorophyll content ratio (Table 2) from SoySNP50K-based GWAS using EMMAX. However, this SNP marker was undetected after one step of MLMM and WGRS-based GWAS which could be a spurious association due to confounding between testing markers and kinship [36]. Thus, the locus for salt tolerance on Chr. 13, which was not identified in this study, may carry rare salt tolerant alleles at low frequency in the diverse panel.

As efficient tools for candidate gene prediction, Phytozome and Soybase genome browsers (https://phytozome. jgi.doe.gov/jbrowse/ and https://soybase.org/gb2/ gbrowse/) provided a mechanism to search and predict putative candidate genes for iron deficiency chlorosis [51], nitrogen fixation traits [52], soybean seed germination under salt stress [49], sudden death syndrome resistance [53], Phytophthora sojae resistance [54], and soybean cyst nematode resistance $[55,56]$. Using a similar approach, Glyma.08 g146100 (EamA-like transporter family), Glyma.08 g157400 (SF9 - Callose synthase), Glyma.08 g224400 (V-type $\mathrm{H}^{+}$-transporting ATPase subunit A), and Glyma.08g225500 (SF11 Pyrophosphate-energized membrane proton pump) were predicted as putative candidate genes for salt tolerance that was mapped on Chr. 8 by functional nominations. 
Similar functional genes have been reported controlling salt tolerance or abiotic stress in plants, such as Callose synthase which plays an important role in response to multiple biotic and abiotic stresses, including salt stress $[57,58]$. In addition, V-type $\mathrm{H}^{+}$-transporting ATPase subunit expressed in the roots, energizes sodium sequestration into the central vacuole and enhances salt tolerance in plants [59-61]. Therefore, the putative candidate genes should be considered for post-GWAS analysis such as gene expression.

The association between salt tolerance and structure of the known gene (Glyma03g32900) on Chr. $3[19,23]$ or gene profiling expression of this gene [21] suggests other salt tolerant sources with novel genes for salt tolerance. Three GBMs, Salt-20, Salt14056 and Salt11655, based on the Glyma03g32900 sequence showed a high association with salt tolerance $[20,23]$ and were confirmed in this study. However, a few salt tolerant lines were not a genotype-phenotype match that carried salt sensitive alleles of these GBMs. The results suggest that those salt tolerant lines might have new salt tolerant allele(s) of the Chr. 3 known locus and other lines might carry novel gene(s) for soybean salt tolerance.

\section{Conclusions}

The salt tolerant traits investigated and multiple genomic regions and SNPs identified in this study confirm that salt tolerance is a complex trait with multiple genes and mechanisms involved. The SNP dataset developed from the WGRS was more efficient than those of the SoySNP50K dataset for GWAS to predict minor loci and to pinpoint putative candidate genes for salt tolerance in soybean. The significant genomic regions strongly suggested a minor locus associated with salt tolerance on Chr. 8. The putative candidate genes and the significant SNPs may be useful to study the molecular mechanism and for marker-assisted selection and molecular breeding to improve salt tolerance in soybean. Additionally, six new salt tolerant sources with predicted novel gene(s) should be further investigated to identify additional salt tolerant gene(s). Moreover, using LSS and/or CCR would be simple and efficient in selection for salt tolerance in a practical breeding program as measuring LSC and LCC is time consuming and expensive and the four traits are highly correlated.

\section{Methods}

\section{Plant materials}

A core set of 305 soybean plant introductions (PIs) was selected from the USDA Soybean Germplasm Collection representing wide genetic diversity derived from the SoySNP50K iSelect BeadChip analysis (Drs. Cregan and Song, pers. comm.). This diverse panel had 255 cultivated soybean (Glycine $\max$ ) and 50 wild soybean
(Glycine soja) accessions. In addition, two salt-tolerant genotypes, cultivars Lee and Fiskeby III [20, 62-64], two salt-sensitive genotypes, cultivars Hutcheson and Jackson $[16,18]$, and cultivar, Williams 82 , were also included as checks. According to the Germplasm Resources Information Network-National Plant Germplasm System (GRIN, https://www.ars-grin.gov/npgs) database, this core set contains accessions from maturity group (MG) 000 to $\mathrm{X}$ and originated from 28 different countries (Additional file 10: Table S4). While conducting GWAS, a subset of 234 accessions from this germplasm set was used for a separate association analysis based on the availability of the WGRS-derived $3.7 \mathrm{M}$ SNP dataset (http://www.soybase.org).

\section{Genotypic datasets}

Over 42,000 SNP markers from the Illumina Infinium SoySNP50K iSelect BeadChip [65] were accessed from the soybean database (http://www.soybase.org). Of these, a total of 37,573 SNPs was selected based on the exclusion of SNPs with greater than $5 \%$ missing data and a minor allele frequency (MAF) of less than 5\%. A second SNPs dataset of over 4.7 M SNPs was generated from the United Soybean Boarded-funded whole-genome resequencing (WGRS) project in the Nguyen Lab (http://www.soybase. org). This SNP dataset was further filtered based on the exclusion of the missing data $(>5 \%)$ and MAF $(<5 \%)$ to obtain over 3.7 M qualified SNP using the SNP Variation \& Suites (SVS) program (Golden Helix, Bozeman, MT 59718, USA). This SNP dataset is hereafter referred as the WGRS-derived $3.7 \mathrm{M}$ SNP dataset. Additionally, three GBMs, Salt-20, Salt14056 and Salt11655, that were previously reported [20,23] were also incorporated into these SNP marker datasets.

\section{Phenotyping}

Soybean lines of the diverse panel were evaluated for salt tolerance under greenhouse conditions following a previously described method [66] with minor modifications. The experimental design was a randomized block with 3 replications blocked over time. Five seedlings of each line were grown per cone-tainer and evaluated in a greenhouse at the University of Missouri, Columbia, $\mathrm{MO}$, using artificial lights and a $13 \mathrm{~h}$ photoperiod from September to December 2016. Soybean seedlings at the growth stage V2 [67] were treated with salt water by exposing seedlings in cone-tainers to a $120 \mathrm{mM} \mathrm{NaCl}$ solution in a tank. The salt solution in the tank was kept at one-third $(7 \mathrm{~cm})$ from the bottom of cone-tainers for 7 $\mathrm{h} /$ day. When the salt-sensitive checks showed severe leaf scorch, which typically appears approx. 2 weeks after the treatment, leaf scorch score (LSS) was visually scored for each plant using a 1-5 scale, where $1=$ no apparent chlorosis; $2=$ slight ( $25 \%$ of the leaves showed chlorosis); 
$3=$ moderate $(50 \%$ of the leaves showed chlorosis and some necrosis); $4=$ severe chlorosis $(75 \%$ of the leaves showed chlorosis and severe necrosis); and $5=$ dead (leaves showed severe necrosis and were withered), mean of LSS of each line was then calculated as previously described [66]. Leaf chlorophyll content was measured for the topmost fully expanded leaf 1 day before and about 14 days after the salt treatment using a chlorophyll meter (Chlorophyll meter SPAD-502, Konica Minolta, Inc., Osaka, Japan) to calculate chlorophyll content ratio (CCR) [20].

Combined trifoliate leaves of five seedlings from each soybean line were harvested after being read for leaf scorch score and chlorophyll content and dried at $60^{\circ} \mathrm{C}$ for 7 days. The dried leaf tissue was ground using a Thomas Model ED-5 laboratory Wiley mill (Thomas Scientific, Swedesboro, NJ, USA) for analyzing leaf chloride (LCC) and leaf sodium (LSC) contents at the Delta Research Center, University of Missouri, Portageville, MO [20, 64]. Briefly, sodium concentration was determined by processing ground leaf tissue $(0.25 \mathrm{~g})$ with a modified wet acid dilution and measuring in an atomic absorption spectrophotometer (Perkin-Elmer ${ }^{\mathrm{rm}}$, Wellesley, MA, USA). Standard reference curves were established for calibration of 25, 50, 100 and $500 \mathrm{mg} \mathrm{kg}^{-1}$ of chloride. Then chloride concentration in solution of $0.15 \mathrm{~g}$ ground leaf tissue was measured using an ion specific electrode in a Fisher Scientific AR 50 dual channel $\mathrm{pH}$, ion, conductivity-meter (Fischer Scientific, Pittsburg, PA, USA). Finally, sodium and chloride concentrations were converted to $\mathrm{mg}$ per $\mathrm{kg}$ of dry leaf tissue for leaf sodium content (LSC) and leaf chloride content (LCC).

\section{Phenotypic data analysis}

Analysis of variance (ANOVA) and the estimation of variance components of phenotypic data were performed using the PROC GLM procedure of SAS 9.4 [68]. Broad-sense heritability $\left(\mathrm{H}^{2}\right)$ of four salt tolerance associated traits were calculated using the following equation for randomized block design: $\mathrm{H}^{2}=\sigma_{\mathrm{g}}^{2} /\left(\sigma_{\mathrm{g}}^{2}+\sigma_{\mathrm{e}}^{2}\right)$, where $\sigma_{\mathrm{g}}$ is the genotypic variance and $\sigma_{\mathrm{e}}$ is the error variance $[69,70]$. Soybean lines were grouped into salt tolerant and salt sensitive groups based on combining all four salt tolerant traits using Euclidean distances in NTSYSpc 2.1 [71]. In addition, the Pearson correlations were also calculated to measure the degree of linear relationship between each pairs of traits and the individual hypothesis tests of the correlations were performed at $\alpha=0.01$ using Minitab 17 [72].

\section{Genome-wide association study (GWAS)}

Linkage disequilibrium (LD) and correlation coefficients $\left(r^{2}\right)$ were measured on all adjacent pairs within each chromosome and a fitted curve was computed based on nonlinear regression of $\operatorname{LD}\left(r^{2}\right)$ on distance $(\mathrm{kb})$ as previously defined [73]. Principle components (PCs) and kinship matrix (relatedness) were applied to correct for population structure and relatedness in mixed linear models. Principal component analysis (PCA) was done for all filtered SNPs with MAF $>0.05$ and the call rate > 0.95 . Number of PCs were selected to add in models when an inflation factor $(\lambda)$ of $p$-value was close to one $[74,75]$ using a genotype association test with a PCs correction in SNP \& Variation Suite (SVS) v8.7.0 software (Golden Helix, Bozeman, MT, USA). Identity by state (IBS) matrices indicated relatedness among soybean accessions calculated using TASSEL 5 [76] to construct phylogenic trees in MEGA 7 [77] and to apply as kinship matrix in GWAS. Genome-wide associations between SNPs and salt tolerant trait were identified using the efficient mixed-model association expedited (EMMAX) and multi-locus mixed model (MLMM) with correction for population structure and relatedness in the SVS software (Golden Helix, Bozeman, MT, USA). False positives were controlled by multiple test correction with false discovery rate $(\mathrm{FDR}) \leq 0.05[78]$ and the threshold of $-\log 10(p-$ value) for identifying significant associations was calculated at FDR $=0.05$. The significant SNPs associated with salt tolerant traits were counted with larger $-\log 10(p$-value) than the threshold that was calculated based on $P$-value using the False Discovery Rate correction (Benjamini-Hochberg) and causal SNPs surrounding the known gene for salt tolerance on Chr. 3 [17, 19, 21].

\section{Candidate genes of salt tolerance}

The soybean genomic data, the soybean genome assembly (Wm82.a2.v1), was integrated with the genomic scale data visualization tool by importing to the GWAS project created in the SVS software (Golden Helix, Bozeman, MT, USA). The search for candidate genes was conducted by zooming in at positions of the significant SNPs associated with salt tolerant traits. Information about the candidate gene was displayed by automatically linking with the Genome Browser of phytozome website (https://phytozome.jgi.doe.gov/jbrowse/). The results were double checked by searching the SoyBase Wm80 Genome Browser (https://soybase.org/gb2/gbrowse/).

\section{Identification of new sources of salt tolerance using gene- based markers}

The soybean lines from salt tolerant group based on their phenotypes were selected to evaluate matching genotypes of GBMs. The salt tolerant lines that did not match the genotypes of GBMs were identified as new sources that may carry new salt tolerant gene(s) in addition to the known gene on Chr. 3 [17, 19, 21]. Moreover, recombination between three GBMs in the salt tolerant lines was considered as new allele(s) of the locus on Chr. 3 for salt tolerance. 


\section{Additional files}

Additional file 1: Table S1. Variation of salt tolerance of checks grown under $120 \mathrm{mM} \mathrm{NaCl}$ treatment. (DOCX $12 \mathrm{~kb}$ )

Additional file 2: Figure S1. Comparisons of salt tolerance based on leaf scorch between soybean cultivars. Fiskeby III and Lee (salt tolerant checks), Hutcheson and Jackson (salt sensitive checks), Williams 82 (the soybean reference cultivar). (JPG $6832 \mathrm{~kb}$ )

Additional file 3: Figure S2. Linkage disequilibrium (LD) decay plot of coefficient of correlation $\left(r^{2}\right)$ between adjacent marker pairs and genomic distance (kb). The fitted curves are based on nonlinear regression using SoySNP50K dataset from 305 diverse genotypes (yellow) and using $3.7 \mathrm{M}$ SNP dataset in the subset from 234 genotypes selected from the original 305 accessions (b/ue). (JPG $1168 \mathrm{~kb}$ )

Additional file 4: Table S2. Genomic inflation factor $(\lambda)$ of models for analyzing association with salt tolerance among soybean accessions using both datasets. (DOCX $13 \mathrm{~kb}$ )

Additional file 5: Figure S3. Quantile-quantile $(\mathrm{Q}-\mathrm{Q})$ plots showing the expected $-\log 10(P)$ compared to the observed $-\log 10(P)$. The results of statistical testing (EMMAX) for association across 37,573 SNPs from SoySNP50K dataset with leaf scorch score (A), chlorophyll content ratio (B), leaf sodium content (C) and leaf chloride content (D) among 305 genetically diverse soybean genotypes. Most SNPs matched with solid lines [expected $-\log 10(P)=$ observed $-\log 10(P)$ ] were unassociated SNPS, on the other hand, sharp curves at the end are the number of true associations. (JPG $4403 \mathrm{~kb}$ )

Additional file 6: Figure S4. Manhattan plots showing association of SNPs distributed throughout 20 chromosomes with four traits. The results based on analyzing GWAS of leaf scorch score (LSS), chlorophyll content ratio (CCR), leaf sodium content (LSC) and leaf chloride content (LCC) using 37,573 SNPs from SoySNP50K dataset from the subset of 234 diverse accessions selected from the original 305 accessions. (JPG $2008 \mathrm{~kb}$ )

Additional file 7: Figure S5. Quantile-quantile (Q-Q) plots showing the expected $-\log 10(P)$ compared to the observed $-\log 10(P)$. The results of statistical testing (EMMAX) for association across 2,280,225 polymorphic SNPs from 3.7 M SNP dataset with leaf scorch score (A), chlorophyll content ratio (B), leaf sodium content (C) and leaf chloride content (D) in the subset of 234 soybean lines selected from the original population of 305 genotypes. SNPs matched with solid lines [expected $-\log 10(P)=$ observed $-\log 10(P)]$ were unassociated SNPs, on the other hand, sharp curves at the end presented the number of true associations. (JPG $4813 \mathrm{~kb}$ )

Additional file 8: Table S3. The genes underlying the significant genomic regions associated with salt tolerance from Phytozome and Soybase databases. (XLSX 24 kb)

Additional file 9: Figure S6. The significant SNPs underlying the known gene (Glyma03g32900) on Chr. 3 (red dots) associated with salt tolerance. The known gene (Glyma03g32900) named in SoyBase Wm82 Genome Browser version 1, and LD block in this genomic region. (JPG $647 \mathrm{~kb})$

Additional file 10: Table S4. A core set of 305 soybean plant introductions (PIs) selected from the USDA Soybean Germplasm Collection. (XLSX 27 kb)

\section{Abbreviations}

CCR: Chlorophyll content ratio; GBM: Gene-based marker; GWAS: Genomewide association study; LCC: Leaf chloride content; LD: Linkage disequilibrium; LSC: Leaf sodium content; LSS: Leaf scorch score; NGS: Nextgeneration sequencing; PCA: Principal component analysis; QTL: Quantitative trait loci; SNP: Single nucleotide polymorphism; WGRS: Whole-genome resequencing

\section{Acknowledgements}

The authors would like to thank Ms. Nguyen Diep Nhu Dang, an intern in the Nguyen Lab, for her technical assistance to the present study in a greenhouse.

\section{Funding}

This present study has received no funding sources from agencies. All costs were obtained from in-kind supports of the Nguyen and Chen Labs, University of Missouri-Columbia.

\section{Availability of data and materials}

The WGRS-derived SNP data was deposited to the Soybase database with Usage Policy applied and can be viewed at (https://soybase.org/projects/SoyBase.B2014.02/resequencing\%20data\%20usage\%20policy.htm).

\section{Authors' contributions}

TDD designed the study, conducted experiments, performed salinity assays and data analysis, and wrote the manuscript; TDV contributed to data analysis, manuscript reviewing and editing; DD and MC analyzed leaf sodium and chloride content; GP contributed to the development of whole-genome resequencing work; $\mathrm{BV}, \mathrm{PC}$, and $\mathrm{DX}$ reviewed and edited the manuscript; HTN and JGS conceived the study, reviewed and edited the manuscript. All authors read and approved the final manuscript.

\section{Ethics approval and consent to participate}

Not applicable.

\section{Consent for publication}

Not applicable.

\section{Competing interests}

The authors declare that they have no competing interests.

\section{Publisher's Note}

Springer Nature remains neutral with regard to jurisdictional claims in published maps and institutional affiliations.

\section{Author details}

${ }^{1}$ Division of Plant Sciences, University of Missouri, Columbia, MO 65211, USA. ${ }^{2}$ Division of Plant Sciences, University of Missouri, Portageville, MO 63873, USA. ${ }^{3}$ Department of Electric Engineering and Computer Science, Christopher S. Bond Life Sciences Center, University of Missouri, Columbia, MO 65211, USA. ${ }^{4}$ Present address: The Cuu Long Delta Rice Research Institute, Thoi Lai District, Can Tho City, Vietnam. ${ }^{5}$ Present Address: Department Agronomy and Plant Genetics, University of Minnesota, St. Paul, MN 55108, USA.

Received: 27 November 2018 Accepted: 31 March 2019

Published online: 25 April 2019

References

1. Wicke B, Smeets $E$, Turkenburg W, Faaij A. The global technical and economic potential of bioenergy from salt-affected soils. Energy Environ Sci. 2011:4:2669-81

2. FAO, ITPS: Status of the world's soil resources (SWSR) - main report. Food and agriculture organization of the United Nations and intergovernmental technical panel on soils, Rome, Italy 2015:pp 124-127.

3. FAO: Crops and drops: Making the best use of water for agriculture. Food and Agriculture Organization of the United Nations, Rome 2002:pp 1-22.

4. Batlle-Sales J: Salinization: An environmental concern under climate change scenarios. In: Proceedings of the Global Forum on Salinization and Climate Change (GFSCC2010), Valencia, 25-29 October 2010. Edited by Thomas RP, vol. III Rome: FAO; 2011: 10.

5. Várallyay $\mathrm{G}$. The impact of climate change on soils and on their water management. Agron Res. 2010;11(Special Issue II):385-96.

6. Bustingorri C, Lavado RS. Soybean growth under stable versus peak salinity. Sci Agric. 2011;68:102-8

7. Papiernik SK, Grieve CM, Lesch SM, Yates SR. Effects of salinity, imazethapyr, and chlorimuron application on soybean growth and yield. Commun Soil Sci Plan. 2005;36(7-8):951-67.

8. Blanco FF, Folegatti MV, Gheyi HR, Fernandes PD. Emergence and growth of corn and soybean under saline stress. Sci Agr. 2007;64(5):451-9.

9. Phang TH, Shao G, Lam HM. Salt tolerance in soybean. J Integr Plant Biol. 2008;50(10):1196-212. 
10. Wang D, Shannon MC. Emergence and seedling growth of soybean cultivars and maturity groups under salinity. Plant Soil. 1999;214(1-2):11724.

11. Essa TA. Effect of salinity stress on growth and nutrient composition of three soybean (Glycine max L. Merrill) cultivars. J Agron Crop Sci. 2002; 188(2):86-93.

12. El-Sabagh A, Sorour S, Ueda A, Saneoka H, Barutcular C. Evaluation of salinity stress effects on seed yield and quality of three soybean cultivars. Azarian J Agric. 2015;2(5):138-41.

13. Rabie RK, Kumazawa K. Effect of salt stress on nitrogen nutrition and yield quality of nodulated soybeans. Soil Sci Plant Nutr. 1988;34(3):385-91.

14. Lee GJ, Carter TE Jr, Villagarcia MR, Li Z, Zhou X, Gibbs MO, Boerma HR. A major QTL conditioning salt tolerance in S-100 soybean and descendent cultivars. Theor Appl Genet. 2004;109(8):1610-9.

15. Hamwieh A, Tuyen DD, Cong H, Benitez ER, Takahashi $\mathrm{R}, \mathrm{Xu} \mathrm{DH}$ Identification and validation of a major QTL for salt tolerance in soybean. Euphytica. 2011;179(3):451-9.

16. Ha BK, Vuong TD, Velusamy V, Nguyen HT, Shannon JG, Lee JD. Genetic mapping of quantitative trait loci conditioning salt tolerance in wild soybean (Glycine soja) PI 483463. Euphytica. 2013;193(1):79-88.

17. Qi X, Li MW, Xie M, Liu X, Ni M, Shao G, Song C, Kay-Yuen Yim A, Tao Y, Wong $\mathrm{FL}$, et al. Identification of a novel salt tolerance gene in wild soybean by whole-genome sequencing. Nat Commun. 2014;5:4340.

18. Hamwieh A, Xu DH. Conserved salt tolerance quantitative trait locus (QTL) in wild and cultivated soybeans. Breeding Sci. 2008;58(4):355-9.

19. Guan RX, Qu Y, Guo Y, Yu LL, Liu Y, Jiang JH, Chen JG, Ren YL, Liu GY, Tian $L$, et al. Salinity tolerance in soybean is modulated by natural variation in GmSALT3. Plant J. 2014;80(6):937-50.

20. Do TD, Vuong TD, Dunn D, Smothers S, Patil G, Yungbluth DC, Chen P, Scaboo A, Xu D, Carter TE, et al. Mapping and confirmation of loci for salt tolerance in a novel soybean germplasm, Fiskeby III. Theor Appl Genet. 2018;131(3):513-24.

21. Do TD, Chen H, Hien VT, Hamwieh A, Yamada T, Sato T, Yan Y, Cong H, Shono $\mathrm{M}$, Suenaga $\mathrm{K}$, et al. $\mathrm{Ncl}$ synchronously regulates $\mathrm{Na}(+), \mathrm{K}(+)$, and $\mathrm{Cl}(-)$ in soybean and greatly increases the grain yield in saline field conditions. Sci Rep. 2016;6:19147.

22. Liu Y, Yu L, Qu Y, Chen J, Liu X, Hong H, Liu Z, Chang R, Gilliham M, Qiu L, et al. GmSALT3, which confers improved soybean salt tolerance in the field increases leaf $\mathrm{cl}$ - exclusion prior to $\mathrm{Na}+$ exclusion but does not improve early vigor under salinity. Front Plant Sci. 2016;7(1485):1485.

23. Patil G, Do T, Vuong TD, Valliyodan B, Lee JD, Chaudhary J, Shannon JG, Nguyen HT. Genomic-assisted haplotype analysis and the development of high-throughput SNP markers for salinity tolerance in soybean. Sci Rep. 2016:6:19199.

24. Chen HT, Cui SY, Fu SX, Gai JY, Yu DY. Identification of quantitative trait loci associated with salt tolerance during seedling growth in soybean (Glycine max L.). Aust J Agric Res. 2008;59(12):1086-91.

25. Zeng A, Lara L, Chen P, Luan X, Hancock F, Korth K, Brye K, Pereira A, Wu C. Quantitative trait loci for chloride tolerance in 'Osage' soybean. Crop Sci. 2017:57:2345-53.

26. Korte A, Farlow A. The advantages and limitations of trait analysis with GWAS: a review. Plant Methods. 2013;9:29.

27. Abdurakhmonov IY, Abdukarimov A. Application of association mapping to understanding the genetic diversity of plant germplasm resources. Int J Plant Genomics. 2008:2008:574927.

28. Flint-Garcia SA, Thornsberry JM, Buckler ES. Structure of linkage disequilibrium in plants. Annu Rev Plant Biol. 2003;54:357-74.

29. Soto-Cerda B, Cloutier S: Association mapping in plant genomes. In: Genetic Diversity in Plants. Edited by Caliskan PM: InTech; 2012: 29-54.

30. Astle W, Balding DJ. Population structure and cryptic relatedness in genetic association studies. Stat Sci. 2009;24(4):451-71.

31. Balding DJ. A tutorial on statistical methods for population association studies. Nat Rev Genet. 2006;7(10):781-91.

32. Simko I, Hu J. Population structure in cultivated lettuce and its impact on association mapping. J Am Soc Hortic Sci. 2008;133(1):61-8.

33. Cappa EP, Martínez MC, Garcia MN, Villalba PV, Marcucci Poltri SN. Effect of population structure and kinship relationships on the results of association mapping tests of growth and wood quality traits in four Eucalyptus populations. BMC Proc. 2011;5(7):P23.

34. Chen H, Wang C, Conomos Matthew P, Stilp Adrienne M, Li Z, Sofer T, Szpiro Adam A, Chen W, Brehm John M, Celedón Juan C, et al. Control for population structure and relatedness for binary traits in genetic association studies via logistic mixed models. Am J Hum Genet. 2016;98(4):653-66.

35. Yu J, Pressoir G, Briggs WH, Vroh Bi I, Yamasaki M, Doebley JF, McMullen MD, Gaut BS, Nielsen DM, Holland JB, et al. A unified mixed-model method for association mapping that accounts for multiple levels of relatedness. Nat Genet. 2006;38(2):203-8.

36. Liu X, Huang M, Fan B, Buckler ES, Zhang Z. Iterative usage of fixed and random effect models for powerful and efficient genome-wide association studies. PLoS Genet. 2016;12(2):e1005767.

37. Segura V, Vilhjalmsson BJ, Platt A, Korte A, Seren U, Long Q, Nordborg M. An efficient multi-locus mixed-model approach for genome-wide association studies in structured populations. Nat Genet. 2012;44(7):825-30.

38. Jaiswal V, Gahlaut V, Meher PK, Mir RR, Jaiswal JP, Rao AR, Balyan HS, Gupta PK. Genome wide single locus single trait, multi-locus and multi-trait association mapping for some important agronomic traits in common wheat (T. aestivum L.). PLoS One. 2016;11(7):e0159343.

39. Dilla-Ermita CJ, Tandayu E, Juanillas VM, Detras J, Lozada DN, Dwiyanti MS, Vera Cruz C, Mbanjo EGN, Ardales E, Diaz MG, et al. Genome-wide association analysis tracks bacterial leaf blight resistance loci in rice diverse germplasm. Rice. 2017;10(1):8.

40. Desgroux A, L'Anthoene V, Roux-Duparque M, Riviere JP, Aubert G, Tayeh N, Moussart A, Mangin P, Vetel P, Piriou C, et al. Genome-wide association mapping of partial resistance to Aphanomyces euteiches in pea. BMC Genomics. 2016;17:124.

41. Li X, Li X, Fridman E, Tesso TT, Yu J. Dissecting repulsion linkage in the dwarfing gene Dw3 region for sorghum plant height provides insights into heterosis. Proc Natl Acad Sci U S A. 2015;112(38):11823-8.

42. Sauvage C, Segura V, Bauchet G, Stevens R, Do PT, Nikoloski Z, Fernie AR, Causse M. Genome-wide association in tomato reveals 44 candidate loci for fruit metabolic traits. Plant Physiol. 2014;165(3):1120-32.

43. Angelovici R, Lipka AE, Deason N, Gonzalez-Jorge S, Lin H, Cepela J, Buell R, Gore MA, DellaPenna D. Genome-wide analysis of branched-chain amino acid levels in Arabidopsis seeds. Plant Cell. 2013;25(12):4827-43.

44. Lee CY, Kim AJ, Lee S, Park YJ. Concept of genome-wide association studies. In: Koh HJ, Kwon SY, Thomson M, editors. Current technologies in plant molecular breeding. Dordrecht: Springer; 2015. p. 175-204.

45. Cao K, Zhou Z, Wang Q, Guo J, Zhao P, Zhu G, Fang W, Chen C, Wang X, Wang $X$, et al. Genome-wide association study of 12 agronomic traits in peach. Nat Commun. 2016;7:13246.

46. Huang $X$, Wei $X$, Sang T, Zhao Q, Feng Q, Zhao Y, Li C, Zhu C, Lu T, Zhang $Z$, et al. Genome-wide association studies of 14 agronomic traits in rice landraces. Nat Genet. 2010;42:961.

47. Jia G, Huang X, Zhi H, Zhao Y, Zhao Q, Li W, Chai Y, Yang L, Liu K, Lu H, et al. A haplotype map of genomic variations and genome-wide association studies of agronomic traits in foxtail millet (Setaria italica). Nat Genet. 2013;45:957.

48. Yano K, Yamamoto E, Aya K, Takeuchi H, Lo P-C, Hu L, Yamasaki M, Yoshida S, Kitano H, Hirano K, et al. Genome-wide association study using wholegenome sequencing rapidly identifies new genes influencing agronomic traits in rice. Nat Genet. 2016:48(8):927-34.

49. Kan G, Zhang W, Yang W, Ma D, Zhang D, Hao D, Hu Z, Yu D. Association mapping of soybean seed germination under salt stress. Mol Gen Genomics. 2015;290(6):2147-62.

50. Zeng A, Chen P, Korth K, Hancock F, Pereira A, Brye K, Wu C, Shi A. Genome-wide association study (GWAS) of salt tolerance in worldwide soybean germplasm lines. Mol Breeding. 2017;37(3):30.

51. Mamidi S, Lee RK, Goos JR, McClean PE. Genome-wide association studies identifies seven major regions responsible for iron deficiency chlorosis in soybean (Glycine max). PLoS One. 2014:9(9).

52. Dhanapal AP, Ray JD, Singh SK, Hoyos-Villegas V, Smith JR, Purcell LC, King CA. Fritschi FB: Genome-wide association analysis of diverse soybean genotypes reveals novel markers for nitrogen traits. Plant Genome-Us. 2015:8(3).

53. Zhang JP, Singh A, Mueller DS, Singh AK. Genome-wide association and epistasis studies unravel the genetic architecture of sudden death syndrome resistance in soybean. Plant J. 2015;84(6):1124-36.

54. Schneider R, Rolling W, Song Q, Cregan P, Dorrance AE, McHale LK. Genome-wide association mapping of partial resistance to Phytophthora sojae in soybean plant introductions from the Republic of Korea. BMC Genomics. 2016;17(1):607.

55. Zhang J, Wen Z, Li W, Zhang Y, Zhang L, Dai H, Wang D, Xu R. Genomewide association study for soybean cyst nematode resistance in Chinese elite soybean cultivars. Mol Breeding. 2017;37(5):60. 
56. Vuong TD, Sonah H, Meinhardt CG, Deshmukh R, Kadam S, Nelson RL, Shannon JG, Nguyen HT. Genetic architecture of cyst nematode resistance revealed by genome-wide association study in soybean. BMC Genomics. 2015;16(1):593.

57. Chen X-Y, Kim J-Y. Callose synthesis in higher plants. Plant Signal Behav. 2009:4(6):489-92.

58. Li S, Zhang L, Wang Y, Xu F, Liu M, Lin P, Ren S, Ma R, Guo Y-D. Knockdown of a cellulose synthase gene BoiCesA affects the leaf anatomy, cellulose content and salt tolerance in broccoli. Sci Rep. 2017;7:41397.

59. Zhang M, Fang $Y$, Liang Z, Huang L. Enhanced expression of vacuolar $H$ +-ATPase subunit $E$ in the roots is associated with the adaptation of Broussonetia papyrifera to salt stress. PLoS One. 2012;7(10):e48183.

60. Golldack D, Dietz K-J. Salt-induced expression of the vacuolar H(+)-ATPase in the common ice plant is developmentally controlled and tissue specific. Plant Physiol. 2001;125(4):1643-54.

61. He X, Huang X, Shen Y, Huang Z. Wheat V-H+-ATPase subunit genes significantly affect salt tolerance in Arabidopsis thaliana. PLoS One. 2014;9(1): e86982.

62. Abel GH. Inheritance of the capacity for chloride inclusion and chloride exclusion by soybeans. Crop Sci. 1969;9:697-8.

63. Abel GH, Mackenzie AJ. Salt tolerance of soybean varieties (Glycine max L. Merill) during germination and later growth. Crop Sci. 1964;4:157-61.

64. Lenis JM, Ellersieck M, Blevins DG, Sleper DA, Nguyen HT, Dunn D, Lee JD, Shannon JG. Differences in ion accumulation and salt tolerance among Glycine accessions. J Agron Crop Sci. 2011;197(4):302-10.

65. Song Q, Hyten DL, Jia G, Quigley CV, Fickus EW, Nelson RL, Cregan PB. Development and evaluation of SoySNP50K, a high-density genotyping array for soybean. PLoS One. 2013;8(1):e54985.

66. Lee JD, Smothers SL, Dunn D, Villagarcia M, Shumway CR, Carter TE, Shannon JG. Evaluation of a simple method to screen soybean genotypes for salt tolerance. Crop Sci. 2008:48(6):2194-200.

67. Fehr WR, Caviness CE, Burmood DT, Pennington JS. Stage of development descriptions for soybeans, Glycine max (L) Merrill. Crop Sci. 1971;11:929-31.

68. SAS Institute Inc.: SAS 9.4 Guide to Software Updates. In., 9.4 edn: Cary, NC: SAS Institute Inc; 2013

69. Sharma JR: Experimental field designs for plant breeding. In: Statistical and biometrical techniques in plant breeding. New Age International (P) Ltd.i 2006: 15-29.

70. Libby WJ. Estimation of variance components of internode length in a cloned population of Mimulus guttatus. Genetics. 1962;47(6):769-77.

71. Rohlf FJ: NTSYS-pc: Numerical Taxonomy and Multivariate Analysis System, Version 2.1. Exeter Software, Setauket, New York 2000.

72. Minitab Inc:: Minitab 17 statistical software [computer software]. In. State College, PA; 2010.

73. Remington DL, Thornsberry JM, Matsuoka Y, Wilson LM, Whitt SR, Doebley J, Kresovich S, Goodman MM, Buckler ES. Structure of linkage disequilibrium and phenotypic associations in the maize genome. Proc Natl Acad Sci U S A. 2001:98(20):11479-84

74. Lo M-T, Hinds DA, Tung JY, Franz C, Fan C-C, Wang Y, Smeland OB, Schork A, Holland D, Kauppi K, et al. Genome-wide analyses for personality traits identify six genomic loci and show correlations with psychiatric disorders. Nat Genet. 2017:49(1):152-6.

75. Li G, Zhu H. Genetic studies: the linear mixed models in genome-wide association studies. Open Bioinforma J. 2013;7:27-33.

76. Bradbury PJ, Zhang Z, Kroon DE, Casstevens TM, Ramdoss Y, Buckler ES. TASSEL: software for association mapping of complex traits in diverse samples. Bioinformatics. 2007;23(19):2633-5.

77. Kumar S, Stecher G, Tamura K. MEGA7: molecular evolutionary genetics analysis version 7.0 for bigger datasets. Mol Biol Evol. 2016:33(7):1870-4

78. Qu HQ, Tien M, Polychronakos C. Statistical significance in genetic association studies. Clin Invest Med. 2010:33(5):E266-70.

\section{Ready to submit your research? Choose BMC and benefit from:}

- fast, convenient online submission

- thorough peer review by experienced researchers in your field

- rapid publication on acceptance

- support for research data, including large and complex data types

- gold Open Access which fosters wider collaboration and increased citations

- maximum visibility for your research: over $100 \mathrm{M}$ website views per year

At BMC, research is always in progress.

Learn more biomedcentral.com/submissions 